EXTENDED REPORT

\title{
Pharmaceutical treatment of symptomatic vertebral fractures in primary care
}

\author{
D J Torgerson, D Sykes, S Puffer, P Brown, C Cooper
}

Ann Rheum Dis 2004;63:853-856. doi: 10.1136/ard.2003.013508

See end of article for authors' affiliations

......................

Correspondence to: Dr David J Torgerson, Department of Health Sciences, University of York, York YO10 5DD dit6@york.ac.uk

Accepted

14 September 2003

\begin{abstract}
Background: Vertebral fractures are associated with a reduction in quality of life and are an important predictor of other non-spine fractures. Previous work has shown that up to $60 \%$ of patients with a vertebral fracture identified in primary care remain untreated.

Objective: To examine the prevalence of pharmaceutical treatment and predictors of treatment in a primary care setting.

Methods: Case-control study using the general practice research database (GPRD). All women aged 50 years and over with a first diagnosis of a vertebral fracture since 1990 were identified and matched with a control by age and practice. Appropriate use of a pharmaceutical agent was defined as a prescription occurring within 30 days of the diagnosis being recorded.

Results: We identified 2719 women with the same number of controls. Within 30 days of diagnosis $61 \%$ of women were prescribed treatment, compared with only $3 \%$ of the controls. Bisphosphonate was the single most important treatment prescribed. Predictors of any drug treatment included: year of fracture (most recent year increased the likelihood of treatment); age (younger patients were more likely to receive treatment); history of back pain; low body weight; history of steroid use.

Conclusions: Treatment of diagnosed vertebral fractures is becoming more common. Treated patients tend to be younger but to have a higher prevalence of clinical risk factors than untreated patients. There remain significant numbers of patients who are not offered treatment.
\end{abstract}

$\mathrm{P}$ revalent and incident vertebral fractures are associated with reduced quality of life $\mathrm{e}^{1}$ and are strong predictors of further fractures, including hip fractures. ${ }^{2}$ Hip fractures are not only extremely costly to society, but they are also associated with substantial reductions in quality of life. Treating patients with a diagnosed vertebral fracture can prevent future vertebral fractures and also lead to a reduction in hip fracture risk. This in turn improves patients' quality of life and can lead to a reduction in direct and indirect financial costs.

Vertebral fractures are underdiagnosed. Furthermore, previous studies have shown that patients with a low-trauma fracture are "undertreated"- that is, they have already sustained one clinically apparent fragility fracture but have received no treatment to prevent future fractures. ${ }^{34}$ In particular, a study looking at women who sustained an incident vertebral fracture reported that only a minority (39\%) were prescribed a pharmaceutical treatment in the 12 months following the diagnosis of the vertebral fracture. ${ }^{4}$

At that time (1995), there were relatively few effective treatments licensed in the United Kingdom for the prevention of vertebral fracture. While hormone replacement therapy (HRT), calcium, and the bisphosphonate etidronate were available, other arguably more effective treatments such as alendronate were either not licensed or were not available until some years later (for example, risedronate and raloxifene). Whether the increased availability of effective treatments for fracture prevention and the production of guidelines for their use (such as the Royal College of Physicians guidelines) has increased the use of preventive treatments is unknown. We addressed this issue in a national, population based cohort-the general practice research database (GPRD). Our objective was to examine the prevalence of pharmacotherapy for osteoporosis among women who sustained a diagnosed incident vertebral fracture between the years 1990 to 2001 .

\section{METHODS}

We identified all women aged 50 years and over who were diagnosed with an incident vertebral fracture between the years 1990 to 2001 and who were registered with a general practice that contributed data to the general practice research database (GPRD). The GPRD is a computerised database that contains the medical records from 683 general practices in the United Kingdom. This is approximately $6 \%$ of the total registered population. The GPRD contains all the routine medical data held on GP computer records (with the patients' names and addresses deleted). Thus it includes demographic and routine clinical information (such as prescription details, clinical events, referrals, and major outcomes) and is representative of the UK primary care population. ${ }^{5}$ A recent validation of the database found that fracture diagnosis was confirmed by an $x$ ray report in more than $85 \%$ of cases. $^{6}$

Because there is evidence that early treatment of vertebral fractures is effective ${ }^{7}$ we classified women as being "treated" if they were treated within 30 days of the diagnosis being made. Treatment was defined as receiving one or more prescriptions of the following drugs: alendronate, risedronate, etidronate, calcium with or without vitamin D, HRT (including tibolone), or raloxifene. For this analysis, women treated after 30 days were classified as being untreated.

As well as identifying the number of women receiving treatment within 30 days, we wanted to determine whether there were any important variables that GPs took into account when they were prescribing treatment. We therefore undertook multivariate analyses to evaluate characteristics that predicted whether a woman was prescribed treatment or not.

To ascertain whether the diagnosis of a vertebral fracture increased the prevalence of treatment relative to no diagnosis, we sampled an equal number of age and practice matched control women. 
Table 1 Absolute number of women diagnosed per year for vertebral fractures

\begin{tabular}{llll}
\hline Year & $\begin{array}{l}\text { Women aged } 50+ \\
\text { years }(\mathbf{n})^{*}\end{array}$ & $\begin{array}{l}\text { Number of } \\
\text { fractures }\end{array}$ & Ratiot \\
\hline 1990 & 290811 & 54 & 0.000186 \\
1991 & 613988 & 175 & 0.000285 \\
1992 & 686706 & 291 & 0.000424 \\
1993 & 673863 & 307 & 0.000456 \\
1994 & 646633 & 331 & 0.000512 \\
1995 & 635176 & 412 & 0.000649 \\
1996 & 509683 & 372 & 0.000730 \\
1997 & 411888 & 301 & 0.000731 \\
1998 & 341415 & 240 & 0.000703 \\
1999 & 253264 & 134 & 0.000529 \\
2000 & 139760 & 67 & 0.000479 \\
2001 & 65608 & 18 & 0.000274 \\
\hline
\end{tabular}

*The number of women in the general practice research database changes over time as the number of participating practices change. tRatio of number of fractures to number of women.

\section{RESULTS}

We identified 2719 women over the age of 50 years who had a first diagnosis of vertebral fracture since 1990, and the same number of controls. Table 1 shows the female population aged 50 years and over that was registered within the GPRD database since 1990, and the absolute numbers of new fracture diagnoses. The table shows that the rate of diagnosis gradually increased until 1997 when it plateaued and started to decline in the last three years from which we have data.

In table 2 we show the characteristics of both groups of women in the 12 months before the cases were diagnosed with a vertebral fracture. The cases tended to have a lower weight than the controls, although this small difference $(<3 \mathrm{~kg})$ was not statistically significant. However, the cases reported significantly more previous non-vertebral fractures than the controls, and a greater prevalence of oral steroid use. Interestingly, the cases also reported a significantly greater prevalence of back pain than the controls, and an increased tendency to use antifracture drugs.

In the 12 months following the diagnosis of a vertebral fracture, anti-fracture drug treatment rose sharply among the cases, unlike the controls. Thus $1653(61.2 \%)$ of the vertebral fracture cases had received a prescription for pharmaceutical treatment within one month of the diagnosis of the index fracture. Interestingly, as table 2 shows, there was a small rise in the use of antifracture agents by the control group-for example, bisphosphonate use rose from $1.1 \%$ to $3.13 \%$ in the controls. Nevertheless, the cases showed a much greater absolute rise in drug use, with the greatest increase for bisphosphonates.
Table 3 shows that the most commonly prescribed treatments were bisphosphonates, followed by calcium. Of the bisphosphonates, etidronate was the most prescribed product. Similar numbers of women were prescribed the other bisphosphonates and HRT. Women using HRT were substantially younger than the cohort as a whole (mean age, 63.7 years). In contrast, women using calcium tended to form the oldest portion of the cohort (mean age, 77.2 years). There was a tendency overall for more younger women to receive treatment than older women. For women aged less than 70 years and for those aged 70 to 75 , similar proportions were treated within 30 days ( 502 women (68.6\%) aged less than 70 years, and 464 women $(68.2 \%)$ aged 70 to 75 years). In contrast, significantly fewer women aged over 75 years received treatment $(393(57.9 \%)$ and $302(48.1 \%)$ for women aged 76 to 82 and $83+$ years, respectively).

Women on treatment tended to be taller and of lower weight than untreated women, although only the weight difference was statistically significant (mean difference 2.2 $\mathrm{kg} ; \mathrm{p}<0.001)$. Women who were prescribed antifracture treatment were more likely to have received oral corticosteroids $(19.3 \%(\mathrm{n}=321), v 13.0 \%(\mathrm{n}=138)$ of women who did not receive antifracture treatment $(\mathrm{p}<0.001))$. However, there was no difference in previous history of non-vertebral fracture. In a stepwise logistic regression model the significant predictors of any treatment prescription were: year of fracture $(\mathrm{OR}=1.06, \mathrm{p}<0.001)$, age $(\mathrm{OR}=0.96, \mathrm{p}<0.001)$, back pain $(\mathrm{OR}=1.59, \mathrm{p}<0.001)$, weight less than $58 \mathrm{~kg}$ $(\mathrm{OR}=1.33, \mathrm{p}=0.01)$, and use of steroids $(\mathrm{OR}=1.58$, $\mathrm{p}<0.001)$. Because women using HRT were so much younger than the rest of the sample, we examined whether excluding this group changed the results. While the odds ratios changed slightly, the same variables remained statistically significant (that is, year of fracture $(\mathrm{OR}=1.08, \mathrm{p}=0.005)$; age $(\mathrm{OR}=0.99, \mathrm{p}=0.002)$, back pain $(\mathrm{OR}=1.57, \mathrm{p}<0.001)$, weight less than $58 \mathrm{~kg}(\mathrm{OR}=1.30, \mathrm{p}=0.005)$, and use of steroids (OR 1.67, p<0.001)).

The proportion of untreated women tended to fall with time. In fig 1 we show the main treatment categories by year of vertebral fracture diagnosis. The number of untreated women fell throughout the 1990s. The addition of new pharmaceutical treatments, such as alendronate, in the mid1990s did not appear to decrease the use of existing drugs; rather there was an increase in the proportion of treated women.

\section{DISCUSSION}

In contrast to a previous study looking at prescription of drugs after vertebral fracture diagnosis, we found the majority of women were prescribed a drug within 30 days of fracture diagnosis. The most common treatments prescribed were etidronate, followed by calcium with vitamin D.

Table 2 Comparison of clinical characteristics and drug use of cases and controls

\begin{tabular}{|c|c|c|c|c|}
\hline Clinical characteristic & Cases $(n=2719)$ & Controls $(n=2719$ ) & Difference $(95 \% \mathrm{Cl})$ & $p$ Value \\
\hline Age (years) & $75(10)$ & $75(10)$ & & \\
\hline Weight $(\mathrm{kg})$ & $61.88(13.14)$ & $64.60(12.89)$ & $2.72(1.91$ to 3.53$)$ & 0.122 \\
\hline Height $(\mathrm{cm})$ & $157.43(13.15)$ & $158.25(13.28)$ & $0.82(-0.46$ to 1.67$)$ & 0.804 \\
\hline Steroid users ( $1+$ prescriptions in year before fracture) & $459(16.9 \%)$ & $121(4.5 \%)$ & $12.43(10.82$ to 14.04$)$ & $<0.001$ \\
\hline Women reporting back pain in year before fracture & $540(19.9 \%)$ & $71(2.6 \%)$ & $17.25(15.64$ to 18.86$)$ & $<0.001$ \\
\hline Number $(\%)$ with a previous non-vertebral fracture. & $864(31.8 \%)$ & $516(19.0 \%)$ & $12.80(10.51$ to 15.08$)$ & $<0.001$ \\
\hline \multicolumn{5}{|l|}{ Bone drug prescriptions } \\
\hline Bisphosphonates & $213(7.8 \%)$ & $31(1.1 \%)$ & $6.70(5.62$ to 7.78$)$ & $<0.001$ \\
\hline HRT & $123(4.5 \%)$ & $94(3.5 \%)$ & $1.00(-0.04$ to 2.04$)$ & 0.045 \\
\hline Calcium and vitamin D & $75(2.8 \%)$ & $24(0.9 \%)$ & $1.90(1.19$ to 2.61$)$ & $<0.001$ \\
\hline Raloxifene & $0(0)$ & $0(0)$ & $0(0)$ & \\
\hline
\end{tabular}

Values are mean (SD) or $\mathrm{n}(\%)$.

$\mathrm{Cl}$, confidence interval; HRT, hormone replacement therapy. 
Table 3 Use of drugs 12 months after diagnosis of vertebral fracture

\begin{tabular}{lllll}
\hline $\begin{array}{l}\text { Bone drug } \\
\text { prescriptions }\end{array}$ & $\begin{array}{l}\text { Cases } \\
(\mathbf{n}=\mathbf{2 7 1 9 )}\end{array}$ & $\begin{array}{l}\text { Controls } \\
(\mathbf{n}=\mathbf{2 7 1 9 )}\end{array}$ & Difference (95\% Cl) & p Value \\
\hline Bisphosphonates & $1347(49.5 \%)$ & $85(3.1 \%)$ & $46.41(44.40$ to 48.38$)$ & $(\mathrm{p}<0.001)$ \\
HRT & $327(12.0 \%)$ & $122(4.5 \%)$ & $7.54(6.10$ to 9.00$)$ & $(p<0.001)$ \\
Calcium and vitamin D & $433(15.9 \%)$ & $70(2.6 \%)$ & $13.35(11.87$ to 14.87$)$ & $(p<0.001)$ \\
Raloxifene & $20(0.7 \%)$ & $0(0)$ & $0.74(1.13$ to 0.44$)$ & $(p<0.001)$ \\
\hline Value are $n$ (\%). & & & \\
Cl, confidence interval; HRT, hormone replacement therapy. &
\end{tabular}

Relatively few women were prescribed raloxifene treatment. This may be because raloxifene was licensed relatively recently compared with the other drugs. We also noted relatively few women using risedronate, probably for the same reason. Drug treatment following vertebral fracture would usually be initiated in primary care and therefore would be identified from the GPRD.

The proportion of women who were offered treatment has increased in the last decade. Thus the proportion of women receiving a bone active agent has increased from less than $20 \%$ in the early 1990 s to over $50 \%$ at the end of the decade. The most significant clinical characteristic associated with a vertebral fracture that appeared to trigger a prescription was the use of corticosteroids. Other common risk factors, such as a previous non-vertebral fracture, were not associated with treatment. We had intended to examine whether the use of bone densitometry had any effect on prescription rates; however, we identified only 10 women $(0.37 \%)$ who had had densitometry measurements recorded.

Clearly we could only examine the prevalence of treatment among women for whom the fracture diagnosis had been made. Most vertebral fractures remain undiagnosed with only about $30 \%$ coming to clinical attention ${ }^{8}$ and probably, therefore, the vast majority of such patients will remain untreated.
Although there has been a welcome increase in the proportion of women receiving treatment for the prevention of fractures, there is still a significant minority with a diagnosed vertebral fracture that remains untreated. Furthermore, while the use of calcium with vitamin D supplementation has been shown to reduce the incidence of non-vertebral fractures within a nursing home environment, other treatments in conjunction with calcium supplementation are more effective. For example, the bisphosphonates (such as risedronate) and raloxifene have been shown in large randomised trials to be more effective at fracture prevention than calcium supplementation alone. ${ }^{9-11}$ Furthermore, bisphosphonate supplementation has been found to be a relatively cost-effective treatment option among women with a previous vertebral fracture. ${ }^{12}$ HRT use was relatively low, probably because of the age of the population. We could not tell whether the use of HRT among women with a vertebral fracture diagnosis fell after the women's health initiative (WHI) study ${ }^{13}$ - which showed increases in breast cancer and cardiovascular events-as our data were obtained before that study was published.

In addition to these findings, we also showed that diagnosed vertebral fracture rates were lower than expected; it is therefore likely that many vertebral fractures remain undiagnosed and hence untreated.

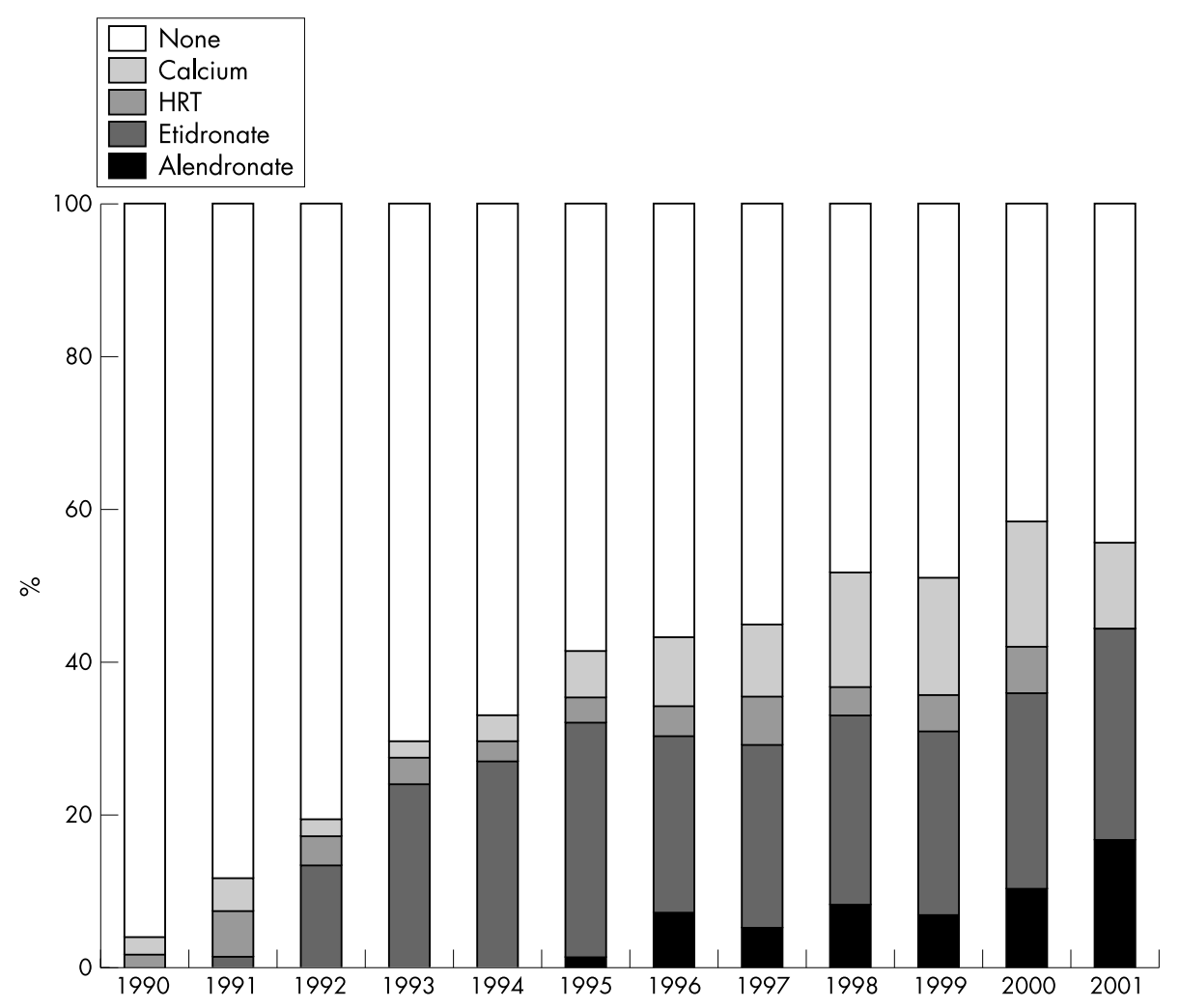

Figure 1 Main treatment categories by year of vertebral fracture diagnosis. 
In conclusion, the use of pharmaceutical treatments has increased with time, but many women remain undertreated.

\section{ACKNOWLEDGEMENTS}

This study was funded by an unrestricted educational grant from Eli Lilly PLC.

\section{Authors' affiliations}

S Puffer, D Torgerson, York Trials Unit, Department of Health Sciences, York University, York, UK

D Sykes, Eli Lilly Pharmaceuticals, Basingstoke, UK

P Brown, Kings Road Surgery, Mumbles, Swansea, UK

C Cooper, MRC Environmental Epidemiology Unit, University of

Southampton, Southampton General Hospital, Southampton, UK

\section{REFERENCES}

1 Oleksik A, Lips P, Dawson A, Minshall ME, Shen W, Cooper C, et al. Healthrelated quality of life in postmenopausal women with low BMD with or without prevalent vertebral fractures. J Bone Miner Res 2000:15:1384-92.

2 Burger H, van Daele PLA, Algra D, Hofman A, Groobbe DE, et al. Vertebral deformities as predictors of non-vertebral fractures. BMJ 1994;309:991-2.

3 Pal B. Questionnaire survey of advice given to patients with fractures. BMJ $1999 \cdot 318 \cdot 500-1$

4 Torgerson DJ, Dolan P. Prescribing by general practitioners after an osteoporotic fracture. Ann Rheum Dis 1998;57:78-9.
5 Walley T, Mantagani A. The UK General practice research database. Lancet 1997;350:1097-9.

6 Van Staa TP, Dennison EM, Cooper C, Beguad B, Zhang B, Leukens HGM. The use of a large pharmacoepidemiologic database to study exposure to oral corticosteroids and risk of fractures: validation of study population and results. Pharmacoepidemiol Drug Safety 2000;9:359-66.

7 Harris ST, Watts NB, Genant HK, McKeever CD, et al. Effects of risedronate treatment on vertebral and nonvertebral fractures in women with postmenopausal osteoporosis. JAMA 1999;282:1344-52.

8 Cooper C, Atkinson EJ, O'Fallon WM, Melton U. The incidence of clinically diagnosed vertebral fractures: a population based study in Rochester, Minnesota, 1985-1989. J Bone Miner Res 1992;7:221-7.

9 McClung MR, Geussens P, Miller PD, Zipple H, Bensen WG, Roux C, et al. Effect of risedronate on the risk of hip fracture in elderly women. N Engl J Med 2001;344:333-40.

10 Black DM, Cummings SR, Karpf DB, Cauley JA, Thompson DE, Nevitt MC, et al. Randomised trial of effect of alendronate on risk of fracture in women with existing vertebral fractures. Lancet, 1996;348:1535-41.

11 Ettinger B, Black DM, Mitlak BH, Knickerbocker RK, Nickelsen T, Genant HK, et al. Reduction of vertebral fracture risk in postmenopausal women with osteoporosis treated with raloxifene. Results from a 3-year randomized clinical trial. Multiple Outcomes of Raloxifene Evaluation (MORE) Investigators. JAMA 1999;282:637-45.

12 Iglesias CP, Torgerson DJ, Bearne A, Bose U. The cost utility of bisphosphonate treatment in established osteoporosis. Q J Med 2002;95:305-11.

13 Women's Health Initiative Investigators. Risks and benefits of estrogen plus progestin in healthy postmenopausal women. Principal results from the women's health initiative randomized controlled trial. JAMA 288:321-33. 